\title{
Impact of 3-Aminopropyltriethoxysilane-Coated Iron Oxide Nanoparticles on Menaquinone-7 Production Using B. subtilis
}

\author{
Dinali Ranmadugala ${ }^{1}$, Alireza Ebrahiminezhad ${ }^{2,3, *}$, Merilyn Manley-Harris ${ }^{1}$ (D), \\ Younes Ghasemi ${ }^{3}$ and Aydin Berenjian ${ }^{1, *}$ \\ 1 Faculty of Science and Engineering, University of Waikato, Hamilton 3216, New Zealand; \\ dinalir@yahoo.com (D.R.); merilyn.manley-harris@waikato.ac.nz (M.M.-H.) \\ 2 Department of Medical Biotechnology, School of Medicine and Noncommunicable Diseases Research Centre, \\ Fasa University of Medical Sciences, Fasa 74615, Iran \\ 3 Department of Pharmaceutical Biotechnology, School of Pharmacy and Pharmaceutical Sciences Research \\ Center, Shiraz University of Medical Sciences, Shiraz 71348, Iran; ghasemiy@sums.ac.ir \\ * Correspondence: a_ebrahimi@sums.ac.ir (A.E.); aydinberenjian@waikato.ac.nz (A.B.); \\ Tel.: +64-7-858-5119 (A.B.)
}

Received: 2 October 2017; Accepted: 20 October 2017; Published: 26 October 2017

\begin{abstract}
One of the major issues associated with industrial production of menaquinone-7 (MK-7) is the low fermentation yield. In this study, we investigated the effect of iron oxide nanoparticles coated with 3-aminopropyltriethoxysilane (IONs@APTES) on the production of MK-7 using B. subtilis (ATCC 6633). Decoration of B. subtilis cells with IONs@APTES significantly enhanced both MK-7 production and yield. An approximately two-fold increase in MK-7 production $(41 \mathrm{mg} / \mathrm{L})$ was observed in the presence of $500 \mu \mathrm{g} / \mathrm{mL}$ IONs@APTES, as compared to MK-7 production using untreated bacteria $(22 \mathrm{mg} / \mathrm{L})$. This paper, therefore, illustrates the immense biotechnological potential of IONs@APTES in increasing MK-7 concentration using B. subtilis, and its future role in bioprocess engineering.
\end{abstract}

Keywords: MK-7; B. subtilis; IONs@APTES; immobilization; fermentation

\section{Introduction}

In terms of human health, the intake of MK-7 plays a vital role in bone formation [1], reducing bone fractures [2], and in preventing postmenopausal bone loss by improving bone mineral calcification and femoral neck width [3]. In addition, a direct link has been observed between MK-7 consumption and improved cardiovascular health. In particular, supplementation of MK-7 has been shown to decrease arterial stiffness in postmenopausal women [4]. Therefore, interest in MK-7 has increased considerably over the past years, and it can be regarded as an obvious choice to be included in multivitamin supplements for the prevention of these diseases [2].

MK-7 can only be produced thorough a fermentation process. Among the bacterial species used in MK-7 production, B. subtilis is one of the most studied and recognized MK-7 producers [5]. Although many studies on MK-7 production have been published using $B$. subtilis, the fermentation process is still not sustainable enough. One of the complications is low fermentation yield [6].

Currently, nanoparticles (NPs) are at the forefront in designing intensified bioprocesses with the combined advantages of reducing downstream processing and maximizing the production of the target products [7]. In terms of bioprocess intensification, NPs have been used to decorate bacterial cells and magnetically separate and re-use them in the fermentation system, which essentially eliminates downstream purification steps such as filtration and centrifugation $[7,8]$. Stepping towards the designing 
of an intensified MK-7 production system, recently, B. subtilis cells were magnetically immobilized with naked iron oxide nanoparticles (IONs) and subsequently recovered from the fermentation media with a high capture efficiency [9]. In addition to reducing the number of downstream processing steps, magnetic immobilization of $B$. subtilis offers the advantages of good mass transport, catalytic stability [10] and improved metabolic activity [7]. Nevertheless, immobilization with naked IONs resulted in lower cell densities and metabolic activity [9]. Further, when naked IONs are used in biological systems, many problems are encountered, such as particle agglomeration, low stability, altered magnetic properties [11], and cytotoxicity [12]. As the interaction of bacteria with nanoparticles is governed by the properties of the bacterial cell wall, as well as the physico-chemical characteristics of the nanoparticles, it is crucial to choose IONs with surface properties that importantly fulfill the fermentation goals; namely, high metabolic activity and biocompatibility.

Recent studies have shown that amine-functionalized nanoparticles have more biological benefits than naked particles, due to their biocompatibility, surface activity, stability and chemical simplicity [12-14]. Compounds such as L-lysine, L-arginine and 3-aminopropyltriethoxysilane (APTES), which introduce amine functional groups to the nanoparticles, have been used to coat negatively charged nanoparticles, thereby increasing the chance of binding nanoparticles to the anionic cell membrane. Previously, IONs coated with L-lysine had been reported to result in no significant inhibitory effect on MK-7 production and cell growth [7]. However, it has now been reported that, in comparison with L-lysine and L-arginine, coating of nanoparticles with APTES prevents the oxidation of nanoparticles, and provides perfect protection for the crystal structure of nanoparticles [13]. Therefore, the present study aimed to synthesize iron oxide nanoparticles coated with 3-aminopropyltriethoxysilane (APTES) and evaluate their effect on MK-7 biosynthesis during B. subtilis fermentation.

\section{Results and Discussion}

\subsection{Synthesis and Characterization of Iron Oxide Nanoparticles Coated with APTES}

The Transmission Electron micrograph of IONs@APTES is presented in Figure 1, showing the spherical-shaped IONs@APTES with a size distribution ranging from of 5 to $17 \mathrm{~nm}$.
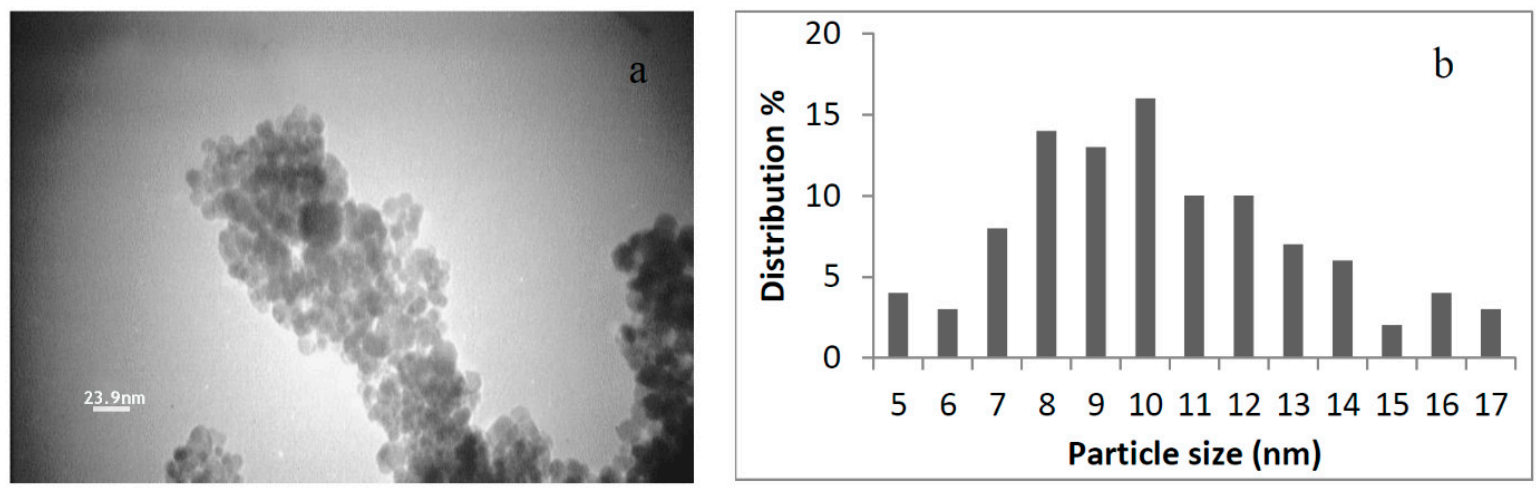

Figure 1. (a) Transmission electron micrograph of IONs@APTES; and (b) Particle size distribution of IONs@APTES.

Figure 2 represents the Fourier transform infrared spectroscopy (FTIR) spectra of IONs@APTES. The Fe-O characteristic peaks of IONs@APTES appeared at about $631.2 \mathrm{~cm}^{-1}$. The $\mathrm{Si}-\mathrm{O}$ bond stretching vibration appeared at $1000.3 \mathrm{~cm}^{-1}$ in IONs@APTES [15]. Peaks at $1622.5 \mathrm{~cm}^{-1}$ and $3426 \mathrm{~cm}^{-1}$ are attributed to $\mathrm{O}-\mathrm{H}$ bending and stretching vibrations of $\mathrm{OH}$ groups [15-19]. Coating of IONs with APTES is established by the presence of peaks at 2910 and $2850 \mathrm{~cm}^{-1}$, which can be attributed to the asymmetric and symmetric $-\mathrm{C}-\mathrm{H}$ stretching vibrations, and are indicative of the presence of aliphatic $-\mathrm{CH}_{2}$ groups. 


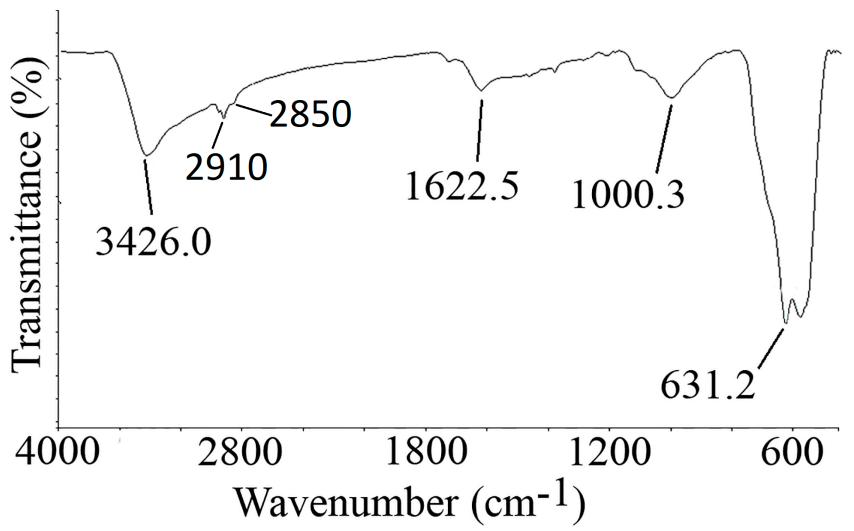

Figure 2. Fourier transform infrared spectroscopy (FTIR) spectra of IONS@APTES.

X-Ray diffraction analysis shows major intensity peaks at $2 \theta$ degrees $30^{\circ}, 35.5^{\circ}, 43^{\circ}, 53^{\circ}, 57^{\circ}$ and $62^{\circ}$. In comparison to standard data for magnetite crystals, the peaks correspond to $220,311,400$, 422,511 and 440 Bragg reflections, confirming the spinal structure of magnetite $\left(\mathrm{Fe}_{3} \mathrm{O}_{4}\right)$. The $2 \theta$ value for the peak at $35.5^{\circ}$ confirmed the predominant magnetite (Figure 3). The crystal size was calculated by using the Scherrer calculator toll on the PANalytical X'Pert HighScore (Produced by PAN alytical B.V., Almelo, The Netherlands, version 1.0d), showing a size of $14 \mathrm{~nm}$.

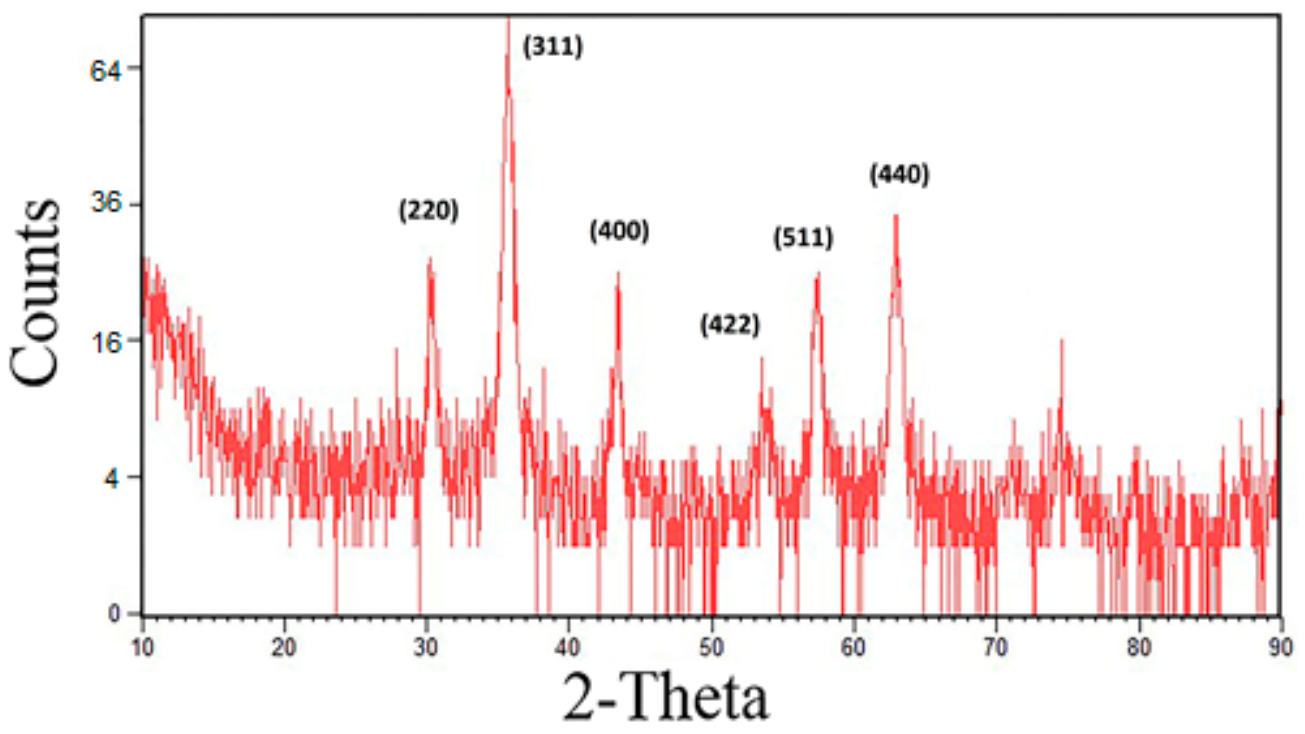

Figure 3. XRD patterns of IONs@APTES.

\subsection{Interaction of B. subtilis Cells with IONs@APTES}

Scanning Electron Microscopy (SEM) was used to observe the interaction of IONs@APTES with B. subtilis cells. IONs@APTES, with their smaller size, high surface area/volume ratio and positively charged amine groups, were readily attached to $B$. subtilis cells when they were grown in the presence of varying IONs@APTES concentrations. Figure 4 illustrates the successful decoration of $B$. subtilis with IONs@APTES in comparison with untreated cells. 

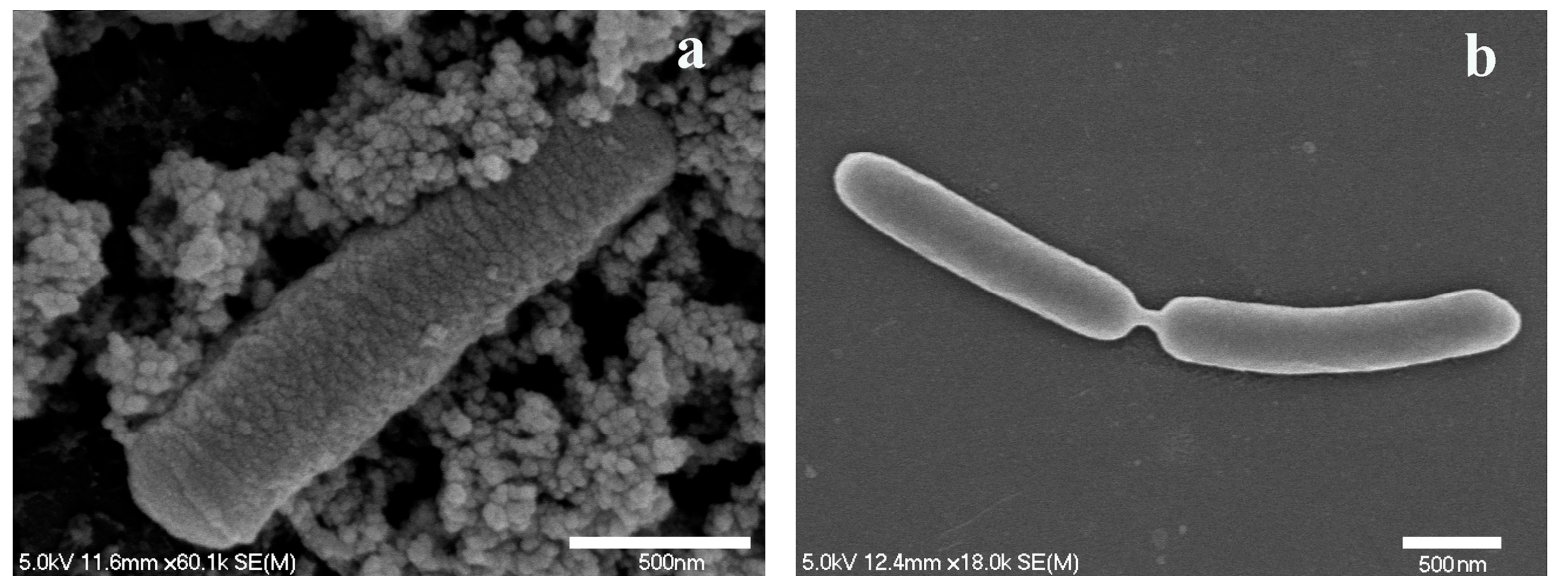

Figure 4. (a) Interaction of IONs@APTES with B. subtilis; (b) B. subtilis in the absence of IONs@APTES.

\subsection{Effect if IONs@APTES on MK-7 Production}

To explore the effect of IONs@APTES on menaquinone production by B. subtilis, MK-7 production was compared in the absence and the presence of varying concentrations of IONs@APTES $(100-700 \mu \mathrm{g} / \mathrm{mL})$. The relationship between IONs@APTES attachment to B. subtilis cells and their effect on MK-7 production is shown in Figure 5. When the concentration of nanoparticles was increased from $100 \mu \mathrm{g} / \mathrm{mL}$ to $500 \mu \mathrm{g} / \mathrm{mL}$ in the fermentation media, MK-7 production increased from 22 to $41 \mathrm{mg} / \mathrm{L}$. However, when the concentration of IONs@APTES was increased beyond $600 \mu \mathrm{g} / \mathrm{mL}$, the increase in MK-7 production was not significantly different from the control sample. The highest MK-7 production of $41 \mathrm{mg} / \mathrm{L}$ was 2-fold higher as compared to untreated bacteria. These results show the key role played by decorating B. subtilis cells with IONs@APTES in enhancing the MK-7 biosynthesis.

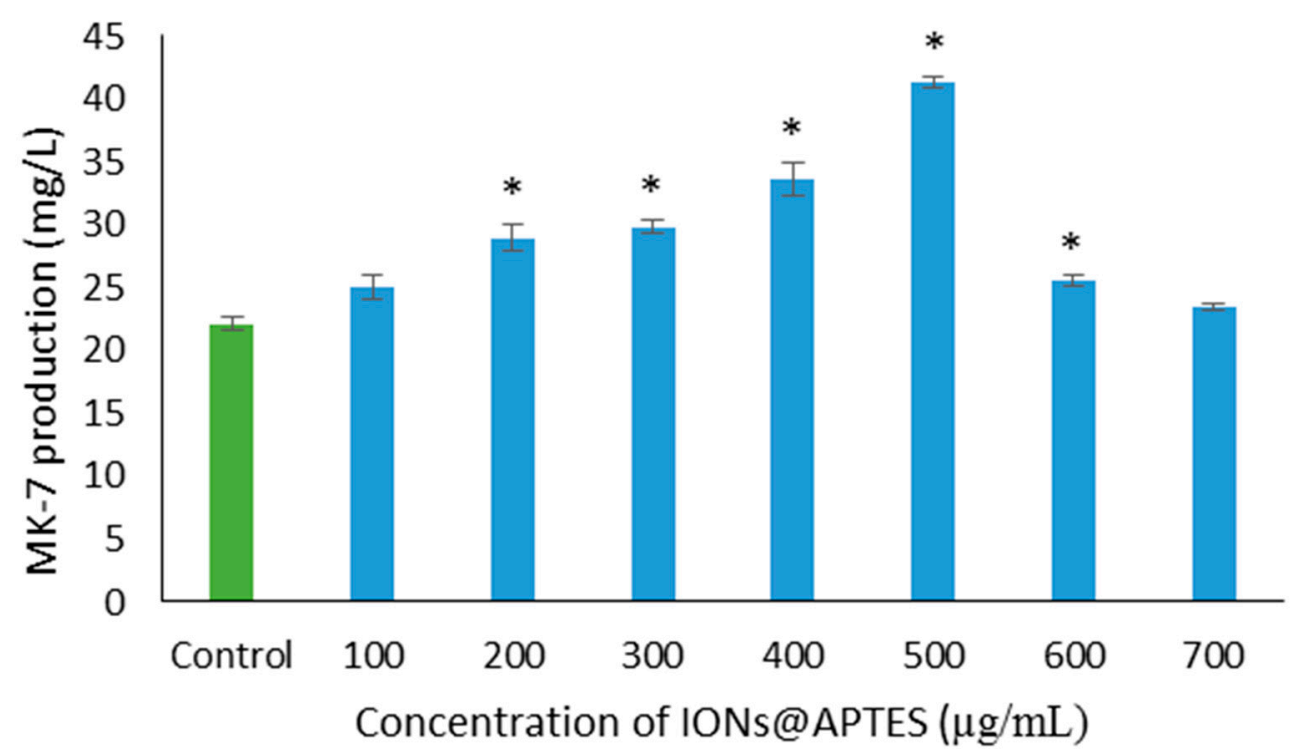

Figure 5. MK-7 production by B. subtilis in the presence of varying concentrations of IONs@APTES and in the absence of nanoparticles. Values are mean \pm S.E. of three replicates. An asterisk indicates a significantly different value from the control $(p<0.05)$.

\subsection{Effect of IONs@APTES on B. subtilis Growth}

The effect of IONs@APTES on B. subtilis growth was also investigated. In this regard, cells were grown for $60 \mathrm{~h}$ in the presence of seven different concentrations of IONs@APTES $(100-700 \mu \mathrm{g} / \mathrm{mL})$ 
and in the absence of nanoparticles (Figure 6). Based on the results, presence of IONs@APTES shows different effects on B. subtilis growth. An increasing trend in B. subtilis cell densities was observed with increase in IONs@APTES concentration up to $500 \mu \mathrm{g} / \mathrm{mL}$. However, there was no statistically significant difference between the samples decorated with 100-400 $\mu \mathrm{g} / \mathrm{mL}$ as compared to the control samples. Concentrations higher than $500 \mu \mathrm{g} / \mathrm{mL}$ of IONs@APTES also led to a decrease in B. subtilis cell density.

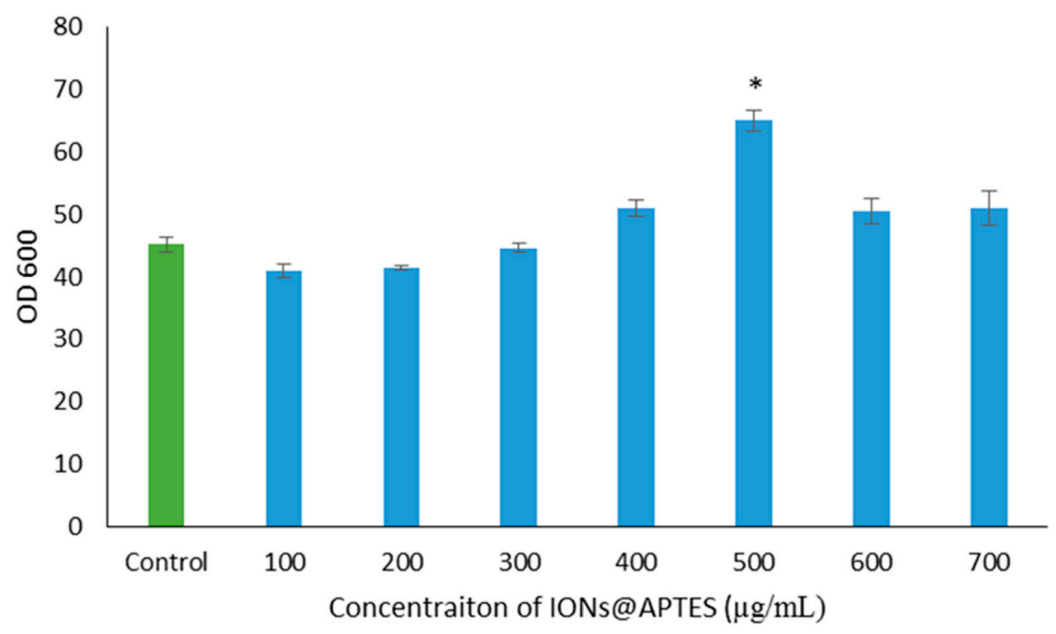

Figure 6. Growth of B. subtilis in the presence of IONS@APTES and in the absence of nanoparticles. Values are mean \pm S.E. of three replicates. An asterisk indicates a significantly different value from the control $(p<0.05)$.

\subsection{Effect of IONs@APTES on MK-7 Yield}

The MK-7 specific yield (Figure 7) was significantly higher in the presence of IONs@APTES in the range of 100 to $500 \mu \mathrm{g} / \mathrm{mL}$ as compared to $B$. subtilis cells growing in the absence of nanoparticles $(p<0.05)$. Therefore, decoration of B. subtilis cells with IONs@APTES significantly influences MK-7 yield in a concentration-dependent manner. The highest $\mathrm{MK}-7$ specific yield of 0.70 was obtained when B. subtilis cells were grown in the presence of $200 \mu \mathrm{g} / \mathrm{mL}$ of IONs@APTES. The MK-7 yield in the absence of nanoparticles was found to be 0.49 . Treatment with $200 \mu \mathrm{g} / \mathrm{mL}$ IONs@APTES increased the B. subtilis MK-7 fermentation yield by approximately 43\%. Therefore, $200 \mu \mathrm{g} / \mathrm{mL}$ of IONs@APTES can be taken as the optimum IONs@APTES concentration to obtain high MK-7 specific yield and high overall productivity during B. subtilis fermentation.

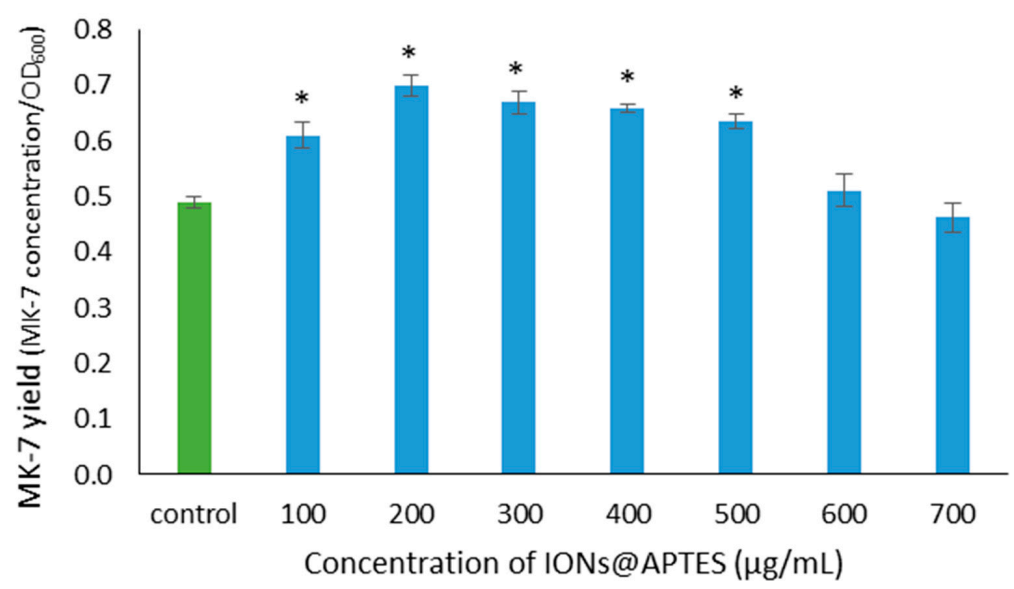

Figure 7. MK-7 yield in the presence of IONs@APTES and in the absence of nanoparticles. Values are mean \pm S.E. of three replicates. An asterisk indicates a significantly different value from the control $(p<0.05)$. 


\subsection{Monitoring the Production of $M K-7$ in the Presence fIONs@APTES}

Figure 8 shows the results of a time-course study of $\mathrm{MK}-7$, cell growth and $\mathrm{pH}$ of $B$. subtilis (ATCC 6633) in the presence of $200 \mu \mathrm{g} / \mathrm{mL}$ IONs@APTES. Growth increased in a time-dependent manner for about $60 \mathrm{~h}$ and reached a maximum cell density of $42.93\left(\mathrm{OD}_{600}\right)$. MK-7 biosynthesis was also started after $24 \mathrm{~h}$ of fermentation and increased during the logarithmic phase. MK-7 production still increased after $B$. subtilis growth reached its highest level. A maximum MK-7 concentration of $37.36 \mathrm{mg} / \mathrm{L}$ was observed when the cell growth was already declining. The $\mathrm{pH}$ of the medium decreased from 7.19 to 6.34 during the first $12 \mathrm{~h}$, and increased gradually up to 8.58 after $84 \mathrm{~h}$, following which it again decreased to 8.04 by the end of fermentation.

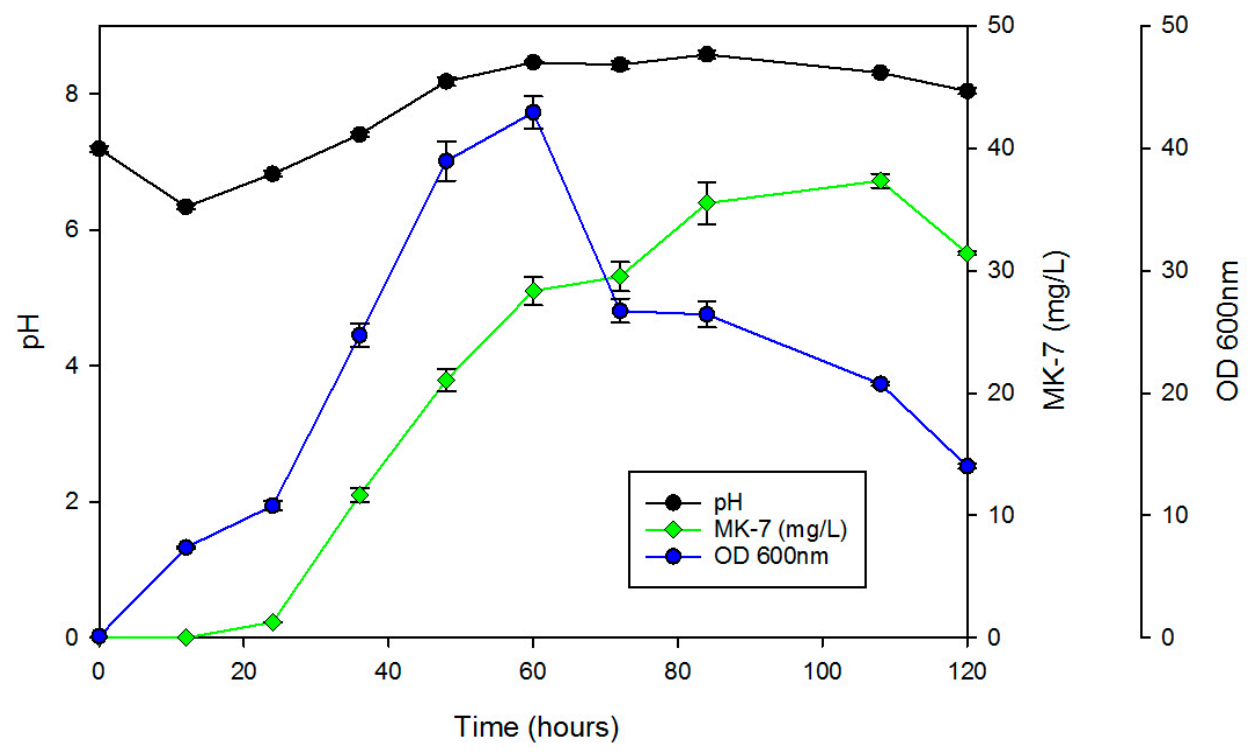

Figure 8. Time course of B. subtilis fermentation in the presence of $200 \mu \mathrm{g} / \mathrm{mL}$ IONs@APTES. Error bars indicate standard error of means.

Treatment with different concentrations of IONs@APTES significantly affected the MK-7 production $(p<0.05)$. In comparison to untreated cells, B. subtilis cells decorated with IONs@APTES showed a significant increase in both MK-7 production and yield. It was, however, apparent that the increase in MK-7 concentration is not merely a reflection on cell density. Binding of IONs@APTES to $B$. subtilis might have changed the state or composition of cell membranes, resulting in enhanced secretion of MK-7 to the fermentation medium $[7,20]$.

Most importantly, IONs@APTES did not show any negative effect on B. subtilis growth within the tested concentrations, indicating that IONs@APTES are clearly compatible with B. subtilis cells. The attachment of NPs to bacteria are governed by physico-chemical interaction between IONs@APTES and B. subtilis cells. While some studies indicate a toxicity effect of positively charged NPs on bacteria, other studies report the attachment without showing any detrimental effect on microorganisms [12]. The interaction of IONs@APTES with B. subtilis cells therefore provides a brand-new domain for enhancing $\mathrm{MK}-7$ production in $B$. subtilis fermentation without resulting in any harmful effect on bacterial growth. Enhancing the production of MK-7 in B. subtilis (ATCC 6633) through the application of nanotechnology has been previously attempted with naked IONs, as well as IONs coated with L-Lysine [7,9], under the same experimental conditions. However, decoration of B. subtilis cells with naked IONs and L-Lysine-coated IONs resulted in lower MK-7 concentrations as compared to untreated cells during a 5-day fermentation course [7]. Therefore, in comparison to naked IONs and L-Lysine-coated IONs, IONs@APTES provide a perfect platform for enhancing the MK-7 yield and the productivity of the fermentation system. 
According to monitoring studies using $200 \mu \mathrm{g} / \mathrm{mL}$ IONs@APTES, production of MK-7 started after $24 \mathrm{~h}$, and reached its maximum of $37.36 \mathrm{mg} / \mathrm{L}$ after $108 \mathrm{~h}$. The results are in agreement with previous studies [21,22] indicating that the production of MK-7 is partly growth-associated. Time course fermentation studies showed that the $\mathrm{pH}$ of the medium decreased from 7.19 to 6.34 during the first $12 \mathrm{~h}$, and increased gradually to 8.18 after $48 \mathrm{~h}$. This increase in $\mathrm{pH}$ might be a result of the production of ammonia during the course of fermentation [23]. However, the increase in $\mathrm{pH}$ showed no negative impact on the MK-7 yield or bacterial growth.

\section{Materials and Methods}

\subsection{Materials}

$\mathrm{FeCl}_{3} \cdot 6 \mathrm{H}_{2} \mathrm{O}, \mathrm{FeSO}_{4} \cdot 4 \mathrm{H}_{2} \mathrm{O}$. 3-aminopropyltriethoxysilane, ammonium hydroxide, yeast extract, glutaraldehyde $25 \%$ aqueous solution, sodium cacodylate Buffer ( $\mathrm{pH}$ 6.5), peptone from soy meal, ethanol absolute for analysis, 2-propanol and $n$-hexane were purchased from Merck (Roger, AR, USA). Lipase enzyme was obtained from Novozymes (Bagsvaerd, Denmark). Pure MK-7 standard (97.6\%) was purchased from ChramoDex (Boulder, CO, USA) for calibration and HPLC analysis. Bacillus subtilis (ATCC 6633) was obtained from the New Zealand reference culture collection (Upper Hutt, New Zealand).

\subsection{Synthesis of Iron Oxide Nanoparticles Surface Functionalized with APTES}

IONs were synthesized by co-precipitation of ferric and ferrous ions with ammonium hydroxide under nitrogen atmosphere as described previously [7,9,12,24-29]. Briefly, $\mathrm{FeCl}_{3} \cdot 6 \mathrm{H}_{2} \mathrm{O}(1.17,3.8 \mathrm{mmol})$ and $\mathrm{FeSO}_{4} \cdot 7 \mathrm{H}_{2} \mathrm{O}(0.74 \mathrm{~g}, 2.2 \mathrm{mmol})$ were dissolved in $50 \mathrm{~mL}$ of distilled water and the solution was vigorously stirred at $70^{\circ} \mathrm{C}$ under nitrogen atmosphere. While stirring was continued, ammonium hydroxide solution $(5 \mathrm{~mL})$ was rapidly injected to the mixture. The reaction was continued for $1 \mathrm{~h}$ and the resultant black precipitate was separated by centrifugation, washed with boiled distilled water, oven dried at $50{ }^{\circ} \mathrm{C}$ overnight, and stored under inert atmosphere. APTES coating was carried out as described previously [12,13]. Briefly, naked ION particles $(0.7 \mathrm{~g})$ were dissolved in $25 \mathrm{~mL}$ solution of ethanol: water, 1:1 $(v / v)$ and sonicated for $10 \mathrm{~min}$ to get uniform dispersion while were kept in ice bath. APTES solution $(2.8 \mathrm{~mL})$ was injected into the mixture under $\mathrm{N}_{2}$ atmosphere, while maintaining the temperature of the water bath at $40^{\circ} \mathrm{C}$. The reaction was followed for $2 \mathrm{~h}$ at $40^{\circ} \mathrm{C}$ with stirring. The resulting particles were finally precipitated by centrifugation and washed with absolute ethanol and deionised water and oven dried at $50{ }^{\circ} \mathrm{C}$ overnight.

\subsection{Characterization of Iron Oxide Nanoparticles Coated with APTES}

The size and morphology of nanoparticles were measured by TEM (Philips, CM10: HT $100 \mathrm{Kv}$, Eindhoven, The Netherlands). The crystal structure of IONs@APTES was determined by XRD (Siemens D5000) with 2-Theta ranging between $20^{\circ}$ and $90^{\circ}$. FTIR spectra were obtained using a Bruker, Vertex 70, FTIR spectrometer (Bruker, Kassel, Germany) in the range of $4000-400 \mathrm{~cm}^{-1}$.

\subsection{Growth and MK-7 Production of B. Subtilis Cells in the Presence of IONs@APTES}

B. subtilis spores grown up to a turbidity of $0.5 \mathrm{McFarland}$ standard $\left(\mathrm{OD}_{600}=0.1\right)$ were diluted 1:20 with fresh media and incubated in the presence of varying concentrations of IONs@APTES using the optimum MK-7 fermentation medium developed by Berenjian, et al. [30]. McFarland standard was used, as this protocol eliminates the incubation requirement to estimate the number of bacteria. $B$. subtilis cultures without IONs@APTES served as controls. All experiments were conducted with 3 replicates. Vials were incubated for $60 \mathrm{~h}$ at $37^{\circ} \mathrm{C}$ with shaking at $120 \mathrm{rpm}$. Optical density measurements were taken at $600 \mathrm{~nm}$. 


\subsection{MK-7 Extraction}

MK-7 was extracted from the fermentation medium using a mixture of $n$-hexane and 2-propanol. The volume ratio of medium: 2-propanol: $n$-hexane was 3:2:1. Enzymatic hydrolysis of triglycerides were carried out before extraction by adding $1 \%$ lipase powder to the $3 \mathrm{~mL}$ of sample and incubating at $37^{\circ} \mathrm{C}$ for $45 \mathrm{~min}$ in a water bath. A mixture of Ethanol-water $(4 \mathrm{~mL}$ and $2 \mathrm{~mL})$ was added to the reaction mixture before extracted with $2 \mathrm{~mL}$ of 2-propanol and $1 \mathrm{~mL}$ of $n$-hexane by vigorously vortex-mixing for $1 \mathrm{~min}$ and centrifuging for $10 \mathrm{~min}$ at $3000 \mathrm{rev} / \mathrm{min}$.

\subsection{Menaquinone Analysis by High-Performance Liquid Chromatography (HPLC)}

High-performance liquid chromatography (HPLC) HP 2440 (Waters Co., Bedford, MA, USA) with a photo diode array UV detector and Gemini column $(5 \mu \mathrm{m}, 250 \times 4.6 \mathrm{~mm}$, Phenomenex Co., Torrance, CA, USA) was used for measuring the concentration of MK-7. The mobile phase contained 2-propanol and $n$-hexane $(2: 1, v / v)$ with a flow rate of $0.5 \mathrm{~mL} / \mathrm{min}$. The injection loop volume was $20 \mu \mathrm{L}$. Detection was carried out with an excitation wavelength of $248 \mathrm{~nm}$. The concentration was calculated by peak area, using a standard curve from serially diluted $0.2 \mathrm{mg} / \mathrm{mL}$ standard solution of MK-7 (Chromadex).

\subsection{Sample Preparation for SEM}

Bacterial cultures were grown for $60 \mathrm{~h}$ in the presence of varying concentrations of IONs@APTES and in the absence of nanoparticles. Samples were prepared as described previously [12]. Briefly, air-dried bacterial smear was heat-fixed by passing through the flame of a Bunsen burner, and fixed with $2.5 \%$ glutaraldehyde in $0.1 \mathrm{M}$ sodium cacodylate buffer with four changes over $30 \mathrm{~min}$ in room temperature. Slides were rinsed with normal saline four times over $30 \mathrm{~min}$ and the cells were dehydrated through a series of alcohol concentrations (50\%, 75\%, 95\%) for $1 \mathrm{~h}$ in each solution and four changes in absolute ethanol for $20 \mathrm{~min}$. Specimens were subjected to critical point drying (Poloron). Samples were then mounted on aluminium stubs and coated with platinum before examining with a Scanning Electron Microscope (Hitachi S-4700, Tokyo, Japan).

\subsection{Statistical Analysis}

Statistical significance was determined by analysis of variance (ANOVA) and Dunnett multiple comparison tests using IBM SPSS statistics 24. Data were reported as the mean \pm standard error of three replicates. Mean values were considered significantly different at $p<0.05$.

\section{Conclusions}

Cultivation of B. subtilis in the presence of IONs@APTES significantly enhanced the MK-7 yield without showing any inhibitory effect on $B$. subtilis growth. This study provides a great promise for synthesis and application of IONs@APTES in cell immobilization in future bioprocess engineering to overcome the low product yield of MK-7. Therefore, it is of utmost importance to consider the results of the present study for further development of an industrial level production system for MK-7 using IONs@APTES.

Acknowledgments: This study was financially supported by the University of Waikato, New Zealand.

Author Contributions: Dinali Ranmadugala conceived and designed the experiments, performed the experiments, analyzed the data and wrote the manuscript. Alireza Ebrahiminezhad and Younes Ghasemi performed the nanoparticle characterization experiments. Aydin Berenjian, Merilyn Manley-Harris and Alireza Ebrahiminezhad supervised the project and edited the manuscript. All authors discussed the results and commented on the manuscript at all stages.

Conflicts of Interest: The authors declare no conflict of interest. 


\section{References}

1. Tsukamoto, Y.; Ichise, H.; Kakuda, H.; Yamaguchi, M. Intake of Fermented Soybean (Natto) Increases Circulating Vitamin K2 (Menaquinone-7) and $\gamma$-Carboxylated Osteocalcin Concentration in Normal Individuals. J. Bone Miner. Metab. 2000, 18, 216-222. [CrossRef] [PubMed]

2. Cranenburg, E.C.; Schurgers, L.J.; Vermeer, C. Vitamin K: The Coagulation Vitamin that Became Omnipotent. Thromb. Haemost. 2007, 98, 120-125. [CrossRef] [PubMed]

3. Knapen, M.; Schurgers, L.; Vermeer, C. Vitamin K2 Supplementation Improves Hip Bone Geometry and Bone Strength Indices in Postmenopausal Women. Osteoporos. Int. 2007, 18, 963-972. [CrossRef] [PubMed]

4. Knapen, M.; Braam, L.A.; Drummen, N.E.; Bekers, O.; Hoeks, A.; Vermeer, C. Menaquinone-7 Supplementation Improves Arterial Stiffness in Healthy Postmenopausal Women: Double-Blind Randomized Clinical Trial. Thromb. Haemost. 2015, 113, 1135-1144. [CrossRef] [PubMed]

5. Sato, T.; Yamada, Y.; Ohtani, Y.; Mitsui, N.; Murasawa, H.; Araki, S. Production of Menaquinone (Vitamin K 2)-7 by Bacillus subtilis. J. Biosci. Bioeng. 2001, 91, 16-20. [CrossRef]

6. Berenjian, A.; Mahanama, R.; Kavanagh, J.; Dehghani, F. Vitamin K Series: Current Status and Future Prospects. Crit. Rev. Biotechnol. 2015, 35, 199-208. [CrossRef] [PubMed]

7. Ebrahiminezhad, A.; Varma, V.; Yang, S.; Ghasemi, Y.; Berenjian, A. Synthesis and Application of Amine Functionalized Iron Oxide Nanoparticles on Menaquinone-7 Fermentation: A Step towards Process Intensification. Nanomaterials 2016, 6, 1. [CrossRef] [PubMed]

8. Sirkar, K.K.; Luo, R.G.; Xu, Y.; Dai, X.-P. Method and Apparatus for Isolation and Purification of Biomolecules. U.S. Patent 6,986,847 B2, 17 January 2006.

9. Ebrahiminezhad, A.; Varma, V.; Yang, S.; Berenjian, A. Magnetic Immobilization of Bacillus subtilis natto Cells for Menaquinone-7 Fermentation. Appl. Microbiol. Biotechnol. 2016, 100, 173-180. [CrossRef] [PubMed]

10. Ansari, F.; Grigoriev, P.; Libor, S.; Tothill, I.E.; Ramsden, J.J. DBT Degradation Enhancement by Decorating Rhodococcus erythropolis IGST8 with Magnetic $\mathrm{Fe}_{3} \mathrm{O}_{4}$ Nanoparticles. Biotechnol. Bioeng. 2009, 102, 1505-1512. [CrossRef] [PubMed]

11. Ranmadugala, D.; Ebrahiminezhad, A.; Manley-Harris, M.; Ghasemi, Y.; Berenjian, A. Iron Oxide Nanoparticles in Modern Microbiology and Biotechnology. Crit. Rev. Microbiol. 2017, 43, 493-507.

12. Ranmadugala, D.; Ebrahiminezhad, A.; Manley-Harris, M.; Ghasemi, Y.; Berenjian, A. The Effect of Iron Oxide Nanoparticles on Bacillus subtilis Biofilm, Growth and Viability. Process Biochem. 2017, 62, $231-240$. [CrossRef]

13. Ebrahiminezhad, A.; Rasoul-Amini, S.; Kouhpayeh, A.; Davaran, S.; Barar, J.; Ghasemi, Y. Impacts of Amine Functionalized Iron Oxide Nanoparticles on HepG2 Cell Line. Curr. Nanosci. 2015, 11, 113-119. [CrossRef]

14. Ebrahiminezhad, A.; Ghasemi, Y.; Rasoul-Amini, S.; Barar, J.; Davaran, S. Impact of amino-acid coating on the synthesis and characteristics of iron-oxide nanoparticles (IONs). Bull. Korean Chem. Soc. 2012, 33, 3957-3962. [CrossRef]

15. Ebrahiminezhad, A.; Najafipour, S.; Kouhpayeh, A.; Berenjian, A.; Rasoul-Amini, S.; Ghasemi, Y. Facile Fabrication of Uniform Hollow Silica Microspheres Using a Novel Biological Template. Colloids Surf. B 2014, 118, 249-253. [CrossRef] [PubMed]

16. Ebrahiminezhad, A.; Bagheri, M.; Taghizadeh, S.-M.; Berenjian, A.; Ghasemi, Y. Biomimetic Synthesis of Silver Nanoparticles Using Microalgal Secretory Carbohydrates as a Novel Anticancer and Antimicrobial. Adv. Nat. Sci. Nanosci. Nanotechnol. 2016, 7, 1-8. [CrossRef]

17. Ebrahiminezhad, A.; Barzegar, Y.; Ghasemi, Y.; Berenjian, A. Green Synthesis and Characterization of Silver Nanoparticles Using Alcea rosea flower Extract as a New Generation of Antimicrobials. Chem. Ind. Biochem. Eng. Q. 2017, 23, 31-37. [CrossRef]

18. Ebrahiminezhad, A.; Berenjian, A.; Ghasemi, Y. Template Free Synthesis of Natural Carbohydrates Functionalised Fluorescent Silver Nanoclusters. IET Nanobiotechnol. 2016, 10, 120-123. [CrossRef] [PubMed] 
19. Ebrahiminezhad, A.; Davaran, S.; Rasoul-Amini, S.; Barar, J.; Moghadam, M.; Ghasemi, Y. Synthesis, Characterization and Anti-Listeria Monocytogenes Effect of Amino Acid Coated Magnetite Nanoparticles. Curr. Nanosci. 2012, 8, 868-874. [CrossRef]

20. Liu, Y.; Ding, X.-M.; Xue, Z.-L.; Hu, L.-X.; Zhang, N.-J.; Wang, Z.; Yang, J.-W.; Cheng, Q.; Chen, M.-H.; Zhang, Z.-Z. The Change of the State of Cell Membrane can Enhance the Synthesis of Menaquinone in Escherichia coli. World J. Microbiol. Biotechnol. 2017, 33, 52. [CrossRef] [PubMed]

21. Sato, T.; Yamada, Y.; Ohtani, Y.; Mitsui, N.; Murasawa, H.; Araki, S. Efficient Production of Menaquinone (vitamin K2) by a Menadione-Resistant Mutant of Bacillus subtilis. J. Ind. Microbiol. Biotechnol. 2001, 26, 115-120. [CrossRef] [PubMed]

22. Song, J.; Liu, H.; Wang, L.; Dai, J.; Liu, Y.; Liu, H.; Zhao, G.; Wang, P.; Zheng, Z. Enhanced Production of Vitamin K2 from Bacillus subtilis (natto) by Mutation and Optimization of the Fermentation Medium. Braz. Arch. Biol. Technol. 2014, 57, 606-612.

23. Luo, M.-M.; Ren, L.-J.; Chen, S.-L.; Ji, X.-J.; Huang, H. Effect of Media Components and Morphology of Bacillus natto on Menaquinone-7 Synthesis in Submerged Fermentation. Biotechnol. Bioprocess Eng. 2016, 21, 777-786. [CrossRef]

24. Ebrahiminezhad, A.; Ghasemi, Y.; Rasoul-Amini, S.; Barar, J.; Davaran, S. Preparation of Novel Magnetic Fluorescent Nanoparticles Using Amino Acids. Colloids Surf. B 2013, 102, 534-539. [CrossRef] [PubMed]

25. Ebrahiminezhad, A.; Rasoul-Amini, S.; Davaran, S.; Barar, J.; Ghasemi, Y. Impacts of Iron Oxide Nanoparticles on the Invasion Power of Listeria monocytogenes. Curr. Nanosci. 2014, 10, 382-388. [CrossRef]

26. Gholami, A.; Rasoul-Amini, S.; Ebrahiminezhad, A.; Abootalebi, N.; Niroumand, U.; Ebrahimi, N.; Ghasemi, Y. Magnetic Properties and Antimicrobial Effect of Amino and Lipoamino Acid Coated Iron Oxide Nanoparticles. Minerva Biotechnol. 2016, 28, 177-186.

27. Gholami, A.; Rasoul-amini, S.; Ebrahiminezhad, A.; Seradj, S.H.; Ghasemi, Y. Lipoamino Acid Coated Superparamagnetic Iron Oxide Nanoparticles Concentration and Time Dependently Enhanced Growth of Human Hepatocarcinoma Cell Line (Hep-G2). J. Nanomater. 2015, 16, 150. [CrossRef]

28. Ebrahimi, N.; Rasoul-Amini, S.; Ebrahiminezhad, A.; Ghasemi, Y.; Gholami, A.; Seradj, H. Comparative Study on Characteristics and Cytotoxicity of Bifunctional Magnetic-Silver Nanostructures: Synthesized Using Three Different Reducing Agents. Acta Metall. Sin. 2016, 29, 326-334. [CrossRef]

29. Ebrahimi, N.; Rasoul-Amini, S.; Niazi, A.; Erfani, N.; Moghadam, A.; Ebrahiminezhad, A.; Ghasemi, Y. Cytotoxic and Apoptotic Effects of Three Types of Silver-Iron Oxide Binary Hybrid Nanoparticles. Curr. Pharm. Biotechnol. 2016, 17, 1049-1057. [CrossRef] [PubMed]

30. Berenjian, A.; Mahanama, R.; Talbot, A.; Biffin, R.; Regtop, H.; Valtchev, P.; Kavanagh, J.; Dehghani, F. Efficient Media for High Menaquinone-7 Production: Response Surface Methodology Approach. New Biotechnol. 2011, 28, 665-672. [CrossRef] [PubMed]

(C) 2017 by the authors. Licensee MDPI, Basel, Switzerland. This article is an open access article distributed under the terms and conditions of the Creative Commons Attribution (CC BY) license (http:/ / creativecommons.org/licenses/by/4.0/). 